\title{
PENGARUH COGNITIVE BEHAVIORAL THERAPY TERHADAP SELF EFFICACY DAN SELF CARE BEHAVIOR PASIEN HIPERTENSI DI KOTA PALANGKA RAYA
}

\author{
${ }^{1}$ Gad Datak, ${ }^{2}$ Ester Inung Sylvia, ${ }^{3}$ Alfeus Manuntung * \\ 1,2,3Politeknik Kesehatan Kemenkes Palangka Raya
}

\begin{abstract}
ABSTRAK
Perawat sebagai educator (pendidik) dan counselor bagi pasien menurut Orem dalam Tomey dan Alligood (2006) dapat memberikan bantuan pada pasien dalam bentuk supportive-educative system dengan memberikan pendidikan kesehatan ataupun konseling dengan tujuan pasien mampu melakukan perawatan hipertensi secara mandiri. Salah satu teknik konseling yang digunakan adalah Cognitive Behavioral Therapy (CBT) dimana merupakan pendekatan psikoterapi yang digunakan untuk menangani emosi disfungsional, perilaku maladaptif dan proses kognitif dan isinya melalui tujuan yang berorientasi, prosedur sistematis eksplisit. Tujuan penelitian adalah untuk mengetahui pengaruh Cognitive Behavioral Therapy (CBT) terhadap self efficacy dan self care behaviour pasien hipertensi di kota Palangka Raya.
\end{abstract}

Desain yang digunakan dalam penelitian ini adalah quasi experiment dengan design penelitian non randomized control group pretest posttest design. Tehnik pengambilan sampel dalam penelitian ini adalah consecutive sampling, 12 pasien hipertensi di Puskesmas Kayon, Kota Palangka Raya sebagai kelompok intervensi dan 12 pasien hipertensi di Puskesmas Panarung, Kota Palangka Raya sebagai kelompok kontrol.

Hasil penelitian menunjukkan ada bahwa Cognitive Behavioral Therapy (CBT) bermakna meningkatkan self efficacy pasien hipertensi di kota Palangka Raya $(p=0,000)$ dan juga meningkatkan self care behaviour pasien hipertensi di kota Palangka Raya $(p=0,000)$

Rekomendasi dari hasil penelitian ini yaitu Cognitive Behavioral Therapy (CBT) dapat dijadikan tindakan oleh perawat di puskesmas melalui kunjungan rumah pada pasien hipertensi untuk menurunkan komplikasi komplikasi penyakit dan meningkatkan kualitas hidup pasien hipertensi.

Kata Kunci : Cognitive Behavioral Therapy (CBT), hipertensi, self efficacy, self care behaviour

\begin{abstract}
Nurse as educator (educator) and counselor for patients according to Orem in Tomey and Alligood (2006) can provide assistance to patients in the form of supportive-educative system by providing health education or counseling with the goal of treatment of hypertension patients were able to perform independently. One technique used counseling is Cognitive Behavioral Therapy (CBT) which is an approach to psychotherapy that is used to handle the emotions dysfunctional, maladaptive behaviors and cognitive processes and contents through goal-oriented, systematic procedure eksplisit.Tujuan study is to determine the effect of Cognitive Behavioral Therapy (CBT) against self-efficacy and self-care behavior of patients with hypertension in the city of Palangkaraya.

The design used in this study is a quasi experiment with non-randomized study design pretest posttest control group design. Sampling techniques in this study were consecutive sampling, 12 patients with hypertension in the puskesmas Kayon, the city of Palangkaraya
\end{abstract}


as the intervention group and 12 patients with hypertension in the puskesmas Panarung, the city of Palangkaraya as a control group.

The results showed that Cognitive Behavioral Therapy (CBT) significantly improve self efficacy of patients with hypertension in the city of Palangkaraya $(p=0.000)$ and also improve self-care behavior of patients with hypertension in the city of Palangkaraya $(p=0.000)$

Recommendations of the results of this study is Cognitive Behavioral Therapy (CBT) can be used as action by nurses in puskesmas through home visits to patients with hypertension to reduce complications complications of the disease and improve the quality of life of patients hypertension.

Keywords: Cognitive Behavioral Therapy (CBT), hypertension, self-efficacy, self-care behavior

\section{PENDAHULUAN}

Di Indonesia, angka pasien hipertensi mencapai 32 persen pada 2008 dengan kisaran usia di atas 25 tahun. Jumlah pasien pria mencapai 42,7 persen, sedangkan 39,2 persen adalah wanita.Sedangkan data Riset Kesehatan Dasar 2007 menyebutkan, prevalensi nasional hipertensi pada penduduk umur >18 tahun adalah sebesar 29,8\% (berdasarkan pengukuran). Sebanyak 10 provinsi mempunyai prevalensi hipertensi pada penduduk umur $>18$ tahun di atas prevalensi nasional, yaitu Riau, Bangka Belitung, Jawa Tengah, D.I. Yogyakarta, Jawa Timur, NTB, Kalimantan Tengah, Sulawesi Tengah, dan Sulawesi Barat. Secara nasional, 10 kabupaten/kota dengan prevalensi hipertensi pada penduduk umur $>18$ tahun tertinggi adalah Natuna (53,3\%), Mamasa (50,6\%), Katingan (49,6\%), Wonogiri (49,5\%), Hulu Sungai Selatan (48,2\%), Rokan Hilir (47,7\%), Kuantan Senggigi (46,3\%),
Bener Meriah (46,1\%), Tapin (46,1\%), dan Salatiga (45,2\%) (Riskesdas, 2007).

Pasien hipertensi di Kota Palangka Raya dalam 5 tahun terakhir menunjukkan peningkatan yang cukup tajam. Pada tahun 2004 dilaporkan terdapat 1.127 pasien, namun pada tahun 2008 meningkat hampir 6 kali menjadi 6.757 pasien, tahun 2009 dilaporkan sebanyak 6.382 pasien, dan tahun 2010 dilaporkan sebanyak 6.696 pasien (Dinkes Kota Palangka Raya, 2011).

Perawat sebagai educator (pendidik) dan counselor bagi pasien menurut Orem dalam Tomey dan Alligood (2006) dapat memberikan bantuan pada pasien dalam bentuk supportive-educative system dengan memberikan pendidikan kesehatan ataupun konseling dengan tujuan pasien mampu melakukan perawatan hipertensi secara mandiri.

Salah satu teknik konseling yang digunakan adalah Cognitive Behavioral Therapy (CBT) dimana merupakan 
pendekatan psikoterapi yang digunakan untuk menangani emosi disfungsional, perilaku maladaptif dan proses kognitif dan isinya melalui tujuan yang berorientasi, prosedur sistematis eksplisit.

Penelitian Findlow et al (2012) di Charlotte, USA terhadap 190 responden orang Afrika Amerika dengan metode cross sectional menunjukkan bahwa orang Afrika Amerika merasa yakin bahwa hipertensi merupakan suatu keadaan yang dikelola dan mereka yang memiliki pengetahuan tentang perilaku perawatan diri yang tepat merupakan faktor yang penting dalam meningkatkan perawatan diri dan mengontrol tekanan darah.

Berdasarkan data pendahuluan di Puskesmas Panarung Kota Palangka Raya, bahwa tingkat keterlibatan dalam perawatan diri pasien hipertensi masih relatif rendah. Hal ini kemungkinan terjadi karena pasien mengabaikan atau kurang menyadari karakter penyakit yang timbul tenggelam. Self efficacy pasien hipertensi atau keyakinan tentang kemampuannya untuk mengontrol tekanan darah juga masih sangat kurang. Ketika tekanan darah sudah kembali normal, maka pasien cenderung menganggap kesembuhannya permanen. Pemahaman pasien dan kemampuan penatalaksanaan atau perawatan mandiri pasien hipertensi (hypertension self management) juga masih sangat rendah. Ketidakpatuhan terhadap perilaku perawatan diri (self care) ini dapat berdampak buruk terhadap kesehatan yang dialami pasien
hipertensi.Membantu individu untuk memahami bahwa hipertensi merupakan suatu kondisi yang dikelola dapat meningkatkan keyakinan mereka tentang hidup dengan penyakit hipertensi. Self efficacy atau keyakinan terhadap kemampuan seseorang untuk berpartisipasi dalam perilaku tertentu merupakan elemen penting dalam program yang dirancang untuk meningkatkan manajemen diri pasien hipertensi.

Berdasarkan hal tersebut di atas maka dilakukan penelitian tentang pengaruh Cognitive Behavioral Therapy (CBT) terhadap self efficacy dan self care behavior pada pasien hipertensi Kota Palangka Raya. Penelitian ini bertujuan untuk mengetahui pengaruh Cognitive Behavioral Therapy (CBT) terhadap self efficacy dan self care behaviour pasien hipertensi di kota Palangka Raya.

\section{METODE PENELITIAN}

Desain yang digunakan dalam penelitian ini adalah quasi experiment dengan design penelitian non randomized control group pretest posttest design. Populasi adalah seluruh pasien hipertensi di seluruh Puskesmas di Kota Palangka Raya. Sampel dalam penelitian ini adalah pasien pasien hipertensi di Puskesmas Panarung dan Puskesmas Kayon di Kota Palangka Raya. Teknik pengambilan sampel dalam penelitian ini adalah consecutive sampling. Kriteria inklusi sampel adalah tidak ada gangguan 
komunikasi verbal, umur 18-60 tahun, terdiagnosa hipertensi minimal 6 bulan dan mendapatkan obat anti hipertensi serta bersedia menjadi responden penelitian Sedangkan kriteria eksklusi sampel adalah tidak mampu berkomunikasi secara verbal, terdapat keterbatasan mental atau kognitif yang dapat mengganggu penelitian, ada komplikasi serius yang dapat mengganggu penelitian, seperti sakit jantung berat, sakit ginjal berat, dan lainlain serta bersedia diteliti. 12 pasien hipertensi di Puskesmas Kayon, Kota Palangka Raya sebagai kelompok intervensi dan 12 pasien hipertensi di Puskesmas Panarung, Kota Palangka Raya sebagai kelompok kontrol.
Pengumpulan data dalam penelitian ini menggunakan 2 (dua) instrumen penelitian, yaitu Kuesioner SEMH (SelfEfficacy to Manage Hypertension) untuk menilai self-efficacy untuk mengelola penyakit hipertensi dan Kuesioner $\mathrm{H}$ SCALE (Hypertension Self-Care Activity Level Effects) digunakan untuk mengukur self care behavior atau perilaku perawatan mandiri pada penderita hipertensi. Analisis data yang digunakan dalam penelitian ini yaitu, analisis univariat terhadap distribusi frekuensi terhadap usia, jenis kelamin, pendidikan dan pekerjaan. Selanjutnya analisis bivariat untuk mengetahui apakah ada pengaruh yang signifikan antara CBT terhadap self efficay dan self care behavior pasien hipertens.

\section{HASIL}

1. Karakteristik Pasien Hipertensi di Kota Palangka Raya

Tabel 1.

Distribusi Karakteristik Responden Hipertensi di Kota Palangka Raya Periode Oktober-Desember 2014 ( $n=24)$

\begin{tabular}{|l|l|l|l|l|}
\hline Karakteristik & Kelompok & \multicolumn{4}{l|}{} \\
\cline { 2 - 5 } Responden & Kontrol & $\%$ & Intervensi & $\%$ \\
\hline Jenis Kelamin & & & & \\
Laki-laki & 5 & 41,7 & 3 & 25 \\
Perempuan & 7 & 58,3 & 9 & 75 \\
\hline Pendidikan & & & & \\
SD & 0 & 0 & 0 & 0 \\
SMP & 0 & 0 & 0 & 0 \\
SLTA & 10 & 83,3 & 7 & 58,3 \\
PT & 2 & 16,7 & 5 & 41,7 \\
\hline Pekerjaan & & & & \\
Tidak bekerja & 5 & 41,7 & 3 & 25 \\
PNS & 7 & 58,3 & 8 & 66,7 \\
Wiraswasta & 0 & 0 & 1 & 8,3 \\
\hline
\end{tabular}




\begin{tabular}{|l|l|l|l|l|}
\hline Usia & & & & \\
Mean & 54,3 & & 57,38 & \\
Median & 54,50 & & 55 & \\
SD & 3,055 & 13,39 & \\
Min-Mak & $45-59$ & $23-83$ & \\
Cl 95\% & $46,28-55,09$ & $53,79-60,96$ & \\
\hline
\end{tabular}

Berdasarkan tabel di atas, jenis kelamin pasien hipertensi pada penelitian ini paling banyak adalah perempuan, yaitu $7(58,3 \%)$ orang pada kelompok kontrol dan 9 orang $(75 \%)$ pada kelompok intervensi.

Berdasarkan latar belakang pendidikan, terlihat bahwa pasien hipertensi sebagian besar berpendidikan SLTA, dengan 10 orang (83,3\%) pada kelompok kontrol dan 7 orang (58,3\%) pada kelompok intervensi.

Hasil penelitian ini menunjukkan bahwa pasien hipertensi bekerja sebagian besar berprofesi sebagai pegawai negeri sipil, dimana pada kelompok kontrol 7 orang (58,3\%) sedangkan pada kelompok intervensi 8 orang $(66,7 \%)$.
Rata-rata usia pasien hipertensi pada kelompok kontrol adalah 54,3 tahun, median 54,50 tahun dengan standar deviasi 3,05 tahun. Usia termuda 45 tahun dan usia tertua 59 tahun. Dari estimasi interval dapat disimpulkan bahwa $95 \%$ diyakini bahwa rata-rata pasien hipertensi antara 46,28 tahun sampai dengan usia 55,09 tahun. Sedangkan pada kelompok intervensi menunjukkan rata-rata usia pasien hipertensi kelompok intervensi adalah 57,38 tahun, median 55 tahun dengan standar deviasi 13,39 tahun. Usia termuda 23 tahun dan usia tertua 83 tahun. Dari estimasi interval dapat disimpulkan bahwa $95 \%$ diyakini bahwa rata-rata usia pasien hipertensi antara 57,79 tahun dan 60,96 tahun

Tabel 2.

Distribusi Frekuensi Self Efficacy dan Self Care Behaviour Pasien Hipertensi Di Palangka Raya Periode Oktober - Desember Tahun 2014 (n=24)

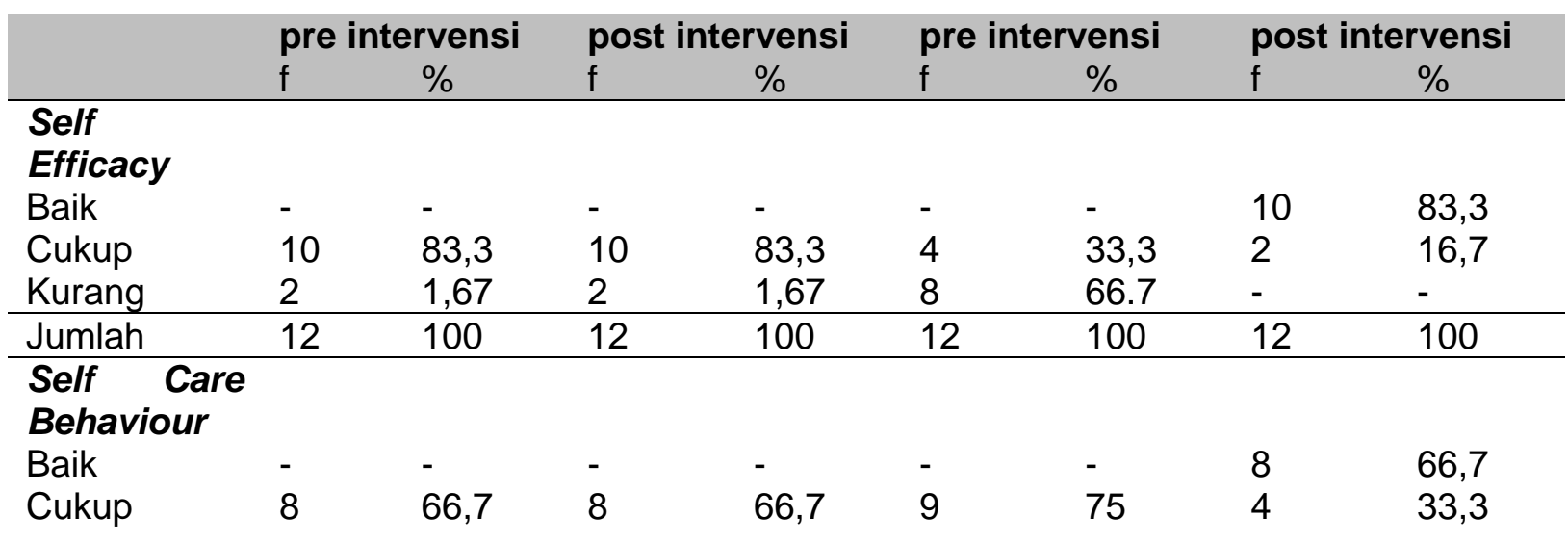




\begin{tabular}{lllllllll} 
Kurang & 4 & 33,3 & 4 & 33,3 & 3 & 25 & - & - \\
\hline Jumlah & 12 & 100 & 12 & 100 & 12 & 100 & 12 & 100 \\
\hline
\end{tabular}

Tabel 2. di atas menunjukkan bahwa sebagaian besar pasien hipertensi yang mendapatkan tindakan Cognitive Behavioral Therapy (CBT) mengalami peningkatan self care efficay dengan kategori baik, yaitu 10 orang $(83,3 \%)$ dan self care behaviour 8 orang (66,7\%).

Tabel 3.

Beda Self Efficacy dan Self Care Behaviour Responden Sebelum dan Sesudah Dilakukan Cognitive Behavioral Therapy (CBT) Di Kota Palangka Raya Periode Oktober -Desember 2014 ( $n=24)$

\begin{tabular}{lcccl}
\hline Variabel & N & Mean & SD & P Value \\
\hline Self Efficacy & & & & \\
Kelompok Kontrol & 12 & 23,08 & 3,099 & 0,000 \\
$\begin{array}{l}\text { Kelompok Intervensi } \\
\text { Self Behaviour }\end{array}$ & 12 & 40,33 & 4,868 & \\
Kelompok Kontrol & 12 & 89,25 & 18,221 & 0,000 \\
Kelompok Intervensi & 12 & 126,08 & 23,612 & \\
\hline
\end{tabular}

Tabel 3. di atas memperlihatkan bahwa rerata nilai self efficacy sebelum dan sesudah pada kelompok kontrol adalah 23,08 (SD=3,009) dan pada kelompok intervensi adalah 40,33 $(S D=4,868)$. Hasil penelitian ini menunjukkan ada perbedaan yang signifikan self efficacy pada pasien hipertensi antara kelompok kontrol dan kelompok intervensi setelah dilakukann Cognitive Behavioral Therapy (CBT) ( $p$ $=0,000)$.

Sedangkan bahwa rerata nilai self care behaviour sebelum dan sesudah pada kelompok kontrol adalah 89,25 $(S D=18,221)$ dan pada kelompok intervensi adalah 126,08 (SD= 23,612).
Hasil penelitian ini menunjukkan ada perbedaan yang signifikan self care behaviour pada pasien hipertensi antara kelompok kontrol dan kelompok intervensi setelah dilakukann Cognitive Behavioral Therapy (CBT) $(p=0,000)$

\section{PEMBAHASAN}

Berdasarkan hasil analisis terhadap penelitian ini bahwan tindakan Cognitive Behavioral Therapy sangat bermaksa untuk meningkatkan self efficacy pasien hipertensi $(p=0,000)$, dimana, self efficacy pada kelompok intervensi sebagian besar mengalami peningkatan dalam kategori baik (83,3\%) dari yang sebelumnya kategori kurang $(66,7 \%)$. Sedangkan pada kelompok kontrol yang tidak mendapatkan 
intervensi sebagian besar responden mempunyai self efficacy dalam kategori cukup (83,3\%), baik sebelum atau sesudah dilakukan penelitian.

Hasil penelitian menunjukkan bahwa terdapat perbedaan tingkat self efficacy pada kedua kelompok pada saat pretest yaitu pada kelompok intervensi lebih rendah daripada kelompok kontrol. Hal ini berhubungan dengan perbedaan faktor predisposisi yang dimiliki oleh kedua kelompok yaitu adanya perbedaan dari latar belakang pendidikan dan pekerjaan, yaitu rata-rata tingkat pendidikan dan pekerjaan pada kelompok intervensi lebih tinggi daripada kelompok kontrol. Perbedaan ini menyebabkan terjadinya perbedaan self efficacy antara kedua kelompok pada saat pretest karena semakin tinggi tingkat pendidikan dan pekerjaan akan mempengaruhi self efficacy seseorang. Hal ini sesuai dengan penelitian Findlow (2012) bahwa semakin tinggi tingkat pendidikan dan latar belakang pendidikan, serta semakin lama waktu penerimaan terhadap penyakitnya akan mempengaruhi self efficacy pasien.

Ajzen (2005) menjelaskan bahwa sikap dan perilaku individu terhadap suatu hal dipengaruhi oleh tiga faktor latar belakang, yakni personal, sosial, dan informasi. Faktor personal adalah sikap umum seseorang terhadap sesuatu, sifat kepribadian (personality traits), nilai hidup (values), emosi, dan kecerdasan yang dimilikinya. Faktor sosial antara lain adalah usia, jenis kelamin (gender), etnis, pendidikan, penghasilan, dan agama. Faktor informasi adalah pengalaman, pengetahuan dan paparan pada media. Perilaku dilakukan karena individu mempunyai minat atau keinginan untuk melakukannya. Minat dan keinginan pasien adalah hal yang penting, pasien perlu menyadari bahwa merekalah yang mengontrol kehidupannya, bukan orang lain, dan mereka yang bertanggung jawab hasil dari perbuatannya dan setiap pasien mempunyai kemampuan untuk berubah.

Penelitian yang dilakukan oleh Craciun (2013) menunjukkan bahwa pendekatan CBT efektif untuk mengurangi keyakinan irasional dan stres. Hasil penelitian ini juga sesuai dengan teori Health Belief Model (HBM) di dalam Edberg (2010) bahwa seseorang yang telah mendapatkan informasi dan keterampilan terkait dengan penyakitnya akan mempunyai persepsi yang baik pula terhadap penyakitnya dan akan membentuk dan memperkuat self efficacy seseorang sebelumnya.Hasil analisis penelitian inti bahwa tindakan Cognitive Behavioral Therapy (CBT) angat bermakna untuk meningkatkan self care behaviuor pasien hipertensi $(p=0,000)$, dimana, self care behaviuor pada kelompok intervensi sebagian besar mengalami peningkatan dalam kategori baik $(66,7 \%)$ dari yang sebelumnya kategori kurang (25\%). Sedangkan pada kelompok kontrol yang tidak mendapatkan intervensi sebagian besar responden mempunyai self efficacy hanya kategori 
cukup $(66,7 \%)$, baik sebelum atau sesudah dilakukan penelitian. Hasil penelitian ini sejalan dengan penelitian yang dilakukan oleh Sung (2012) yang menyatakan bahwa pasien hipertensi yang mendapatkan terapi perilaku kognitif mengalami peningkatan kualitas hidup secara signifikan. Hasil penelitian ini juga relevan dengan penelitian yang dilakukan oleh Arch (2013) yang menunjukkan bahwa CBT efektif dalam mengurangi keparahan diagnosis dan efektif mengurangi kecemasan. Inti penatalaksanaan hipertensi adalah pencegahan pada individu yang memiliki tekanan darah tinggi dengan mengatur pola hidup sehat untuk mengurangi komplikasi hipertensi meliputi manajemen berat badan, menghindari alkohol, berhenti merokok, dan modifikasi diet. Peningkatan kemampuan perawatan diri pasien (self care behavior) pada kelompok intervensitidak terlepas dari proses belajar pasien selama dilakukan intervensi. Setiap perilaku manusia itu merupakan hasil dari proses belajar (pengalaman) dalam merespons berbagai stimulus dari lingkungannya dan dalam proses belajar untuk menghasilkan perilaku tersebut, aspek kognitif memiliki peranan penting terutama dalam mempertimbangkan berbagai tindakan yang hendak dilakukan, menentukan pilihan tindakan, dan mengambil keputusan tindakan perilakunya.
NACBT (2007) menyatakan bahwa pasien melalui $\mathrm{CBT}$ terlibat aktivitas dan berpartisipasi dalam melatih diri dengan cara membuat keputusan, penguatan diri dan strategi lain yang mengacu pada selfregulation. Tujuan dari CBT yaitu mengajak individu untuk belajar mengubah perilaku, menenangkan pikiran dan tubuh sehingga merasa lebih baik, berpikir lebih jelas dan membantu dalam keputusan yang tepat sehingga pada akhirnya dengan CBT diharapkan dapat membantu pasien dalam menyelaraskan dalam berpikir, merasa, dan bertindak.

Oemarjoedi (2003) menyatakan bahwa Cognitive Behavioral Therapy (CBT) dapat menjadi terapi yang efektif untuk berbagai masalah seperti kecemasan, nyeri kronis, depresi, masalah tidur, masalah makan, dan masalah kesehatan umum lainnya. Penyakit kronis seperti hipertensi membutuhkan pendekatan yang berpusat pada pasien, yaitu pemberdayaan pasien yang menekankan pada pendekatan kolaboratif untuk memfasilitasi pasien mengarahkan dirinya dalam perubahan perilaku yang lebih baik. Hal ini sesuai dengan salah satu prinsip Cognitive Behavior Therapy (CBT) yaitu CBT merupakan edukasi yang bertujuan mengajarkan pasien untuk menjadi terapis bagi dirinya sendiri dan menekankan pada pencegahan.

Peningkatan self care behavior pada kelompok intervensi lebih tinggi 
dibandingkan kelompok kontrol karena selama kunjungan rumah pasien mendapatkan intervensi Cognitive Behavioral Therapy (CBT) secara terstruktur. Responden berperan aktif dalam mengikuti setiap sesi selama intervensi. Beck (2011) menyatakan bahwa CBT dapat mengubah sikap dan perilaku seseorang dengan berfokus pada pikiran, keyakinan dan sikap yang kita pegang (proses kognitif) dan bagaimana hal ini berhubungan dengan cara kita berperilaku. Hal ini juga didukung oleh penelitian Shahni (2013) bahwa model kognitif-perilaku secara signifikan dapat meningkatkan self care behavior pada pasien yang menderita penyakit kronis.

\section{KESIMPULAN DAN SARAN}

\section{Cognitive Behavioral Therapy (CBT)}

bermakna meningkatkan self efficacy dan self care behaviour pasien hipertensi di kota Palangka Raya. Cognitive Behavioral Therapy (CBT) dapat dijadikan tindakan oleh perawat di puskesmas melalui kunjungan rumah pada pasien hipertensi untuk menurunkan komplikasi komplikasi penyakit dan meningkatkan kualitas hidup pasien hipertensi.

\section{DAFTAR PUSTAKA}

Ajzen, I., 2005. Attitude, personality, \& behavior. Open University Press.

Arch, J.J., Ayers, C.R., Baker, A. Almklov, E., Dean, D.J., \& Craske M.G., 2013. 'Randomized clinical trial of adapted mindfulness-based stres reduction versus group cognitive behavioral therapy for heterogeneous anxiety disorders'. Behaviour Research and Therapy 51 (2013) 185e196. Diakses dari http://www.sciencedirect.com/ pada tanggal 5 Oktober 2013.

Badan Penelitian dan Pengembangan Kesehatan Kemenkes R.I., 2013. Laporan hasil riset kesehatan dasar (Riskesdas) 2013. Kementerian Kesehatan Republik Indonesia, Jakarta.

Bandura, A., 1994. 'Self-efficacy: toward a unyfying theory of behavioral change'. Psychological Review 1977, vol. 84. no. 2. 191-215. Diakses dari http://www.ou.edu/cls/online/ pada tanggal 20 Oktober 2013.

Bandura, A., 1994. 'Self-efficacy. in v. s. ramachaudran (ed.), encyclopedia of human behavior'. New York: Academic Press, vol. 4, pp. 71-81. Diakses dari

http://www.des.emory.edu/mfp/Ba nEncy.html pada tanggal 20 Oktober 2013.

Bappeda Kota Palangka Raya, 2014. 'Selayang pandang Kota Palangka Raya', 11 Pebruari 2014. Diakses dari http://www.bappeda.palangkaray a.go.id/ pada tanggal $12 \mathrm{Mei}$ 2014.

Beck, Judith S., 2011. Cognitive behavior therapy: basics and beyond.2nd ed. New York: The Guilford Press.

Bosworth, H.B., Olsen, M.K., Grubber J.M., Neary A.M., RN, Orr M.M., Powers B.J., Adams M.B., Svetkey L.P., Reed S.D., Li, Yanhong, Dolor R.J., Oddone E.Z., 2009. 'Two Selfmanagement Interventions to Improve Hypertension Control'. Ann Intern Med. 2009;151:687$695 . \quad$ Diakses dari 
http://www.sciencedirect.com/ pada tanggal 5 Oktober 2013.

Brashers, Valentina L., 2008. Aplikasi klinis patofisiologi: pemeriksaan dan manajemen. edisi 2. Alih bahasa: Kuncara. Jakarta: EGC.

Brennan, L., Walkley, J., Fraser, S.F., Greenway, K., \& Wilks, R., 2008. 'Motivational interviewing and cognitive behaviour therapy in the treatment of adolescent overweight and obesity: study design and methodology'. Contemporary Clinical Trials 29(2008)359-375. Diakses dari http://www.sciencedirect.com/ pada tanggal 15 Oktober 2013.

Cooper, Z., Doll, H.A., Hawker, D.M., Byrne, S., Bonner, G., Eeley, E., O'Connor, M.E., \& Fairburn, C.G., 2010. 'Testing a new cognitive behavioural treatment for obesity: a randomized controlled trial with three-year follow-up'. Behaviour Research and Therapy 48 (2010) 706e713. Diakses dari http://www.sciencedirect.com/ pada tanggal 21 Oktober 2013.

Craciun, B., 2013. 'The efficiency of applying a cognitive behavioral therapy program in diminishing perfectionism, irrational beliefs and teenagers' stres'. ProcediaSosial and Behavioral Sciences 84 (2013) 274-278. Diakses dari http://www.sciencedirect.com/ pada tanggal 5 Oktober 2013.

Currie, S.R., Clark, S., Hodgins, D.C., \& El-Guebaly, N., 2004. 'Randomized controlled trial of brief cognitive-behavioural interventions for insomnia in recovering alcoholics'. Addiction. 2004 Sep;99(9):1121-32. Diakses dari http://www.ncbi.nlm.nih.gov/ pada tanggal 21 Oktober 2013.

Dinas Kesehatan Kota Palangka Raya, 2009. Profil kesehatan Kota Palangka Raya, 2008.
Dinas Kesehatan Kota Palangka Raya, 2010. Profil kesehatan Kota Palangka Raya, 2009.

Dinas Kesehatan Kota Palangka Raya, 2011. Profil kesehatan Kota Palangka Raya, 2010.

Dinas Kesehatan Kota Palangka Raya, 2014. 'UPTD Puskesmas Panarung'. Diakses dari http://www.dinkes.palangkaraya.g o.id/ pada tanggal 12 Mei 2014.

Edberg, M., 2010. Buku ajar kesehatan masyarakat: teori sosial dan perilaku. Alih bahasa: Anwar, dkk, Jakarta: EGC.

Evans, G., Lewin, T.J., Bowen, K., \& Lowe, J., 2009. 'Dealing with anxiety: a pilot cognitive behavioural therapy program for diabetic clinic outpatient attendees'. International Journal of Diabetes Mellitus 2 (2010) 5155. Diakses dari http://www.sciencedirect.com/ pada tanggal 21 Oktober 2013.

Findlow, J.W. \& Seymour, R.B., 2011. 'Prevalence rates of hypertension self-care activities among African Americans'. J Natl Med Assoc. 2011 June; 103(6): 503-512. Diakses dari http://www.ncbi.nlm.nih.gov/pmc I pada tanggal 18 Oktober 2013.

Findlow, J.W., Seymour, R.B., \& Brunner, H.L.R., 2012. 'The association between self-efficacy and hypertension self-care activities among African American adults'. J Community Health. 2012 Feb;37(1):15-24. doi: 10.1007/s10900-011-9410-6.

Diakses dari http://www.ncbi.nlm.nih.gov/ pada tanggal 17 Oktober 2013.

Friedman, Marilyn M., 1998. Keperawatan keluarga: teori dan praktik, ed.3. Jakarta: EGC. 
Ilkhchi, S.V., Poursharifi, H., Alilob, M.M., 2011. 'The effectiveness of cognitive-behavioral group therapy on self efficacy and assertiveness among anxious female students of high schools'. Procedia-Sosial and Behavioral Sciences 30 (2011) 2586-2591. Diakses dari http://www.sciencedirect.com/ pada tanggal 5 Oktober 2013.

Jernelov S., Lekander, M., Blom, K., Rydh, S., Ljótsson, B., Axelsson, J.\& Kaldo, V., 2012. 'Efficacy of a behavioral self-help treatment with or without therapist guidance for co-morbid and primary insomnia-a randomized controlled trial'. BMC Psychiatry. 2012 Jan 22;12:5. Diakses dari http://www.ncbi.nlm.nih.gov/ pada tanggal 21 Oktober 2013.

Lemeshow, S., Hosmer, D.W., Klar, J. \& Lwangsa, S.K., 1990. Adequacy of sample size in health studies. World Health Organization.

Marzocchi, R., Moscatiello, S., Villanova, N., Suppini, A., \& Marchesini, G., 2008. 'Psychological profile and quality of life of morbid obese patients attending a cognitive behavioural program'. Psychological Topics 17 (2008), 2, 349-360. Diakses dari http://www.sciencedirect.com/ pada tanggal 5 Oktober 2013.

Molaie, A., Shahidi, S., Vazifeh, S., \& Bagherian, S., 2010. 'Comparing the effectiveness of cognitive behavioral therapy and movie therapy on improving abstinence self-efficacy in Iranian substance dependent adolescents'.

Procedia Sosial and Behavioral Sciences 5 (2010) 1180-1184. Diakses dari http://www.sciencedirect.com/ pada tanggal 5 Oktober 2013.

Myers, E., Startup, H., \& Freeman, D., 2011. 'Cognitive behavioural treatment of insomnia in individuals with persistent persecutory delusions: a pilot trial'. J. Behav. Ther. \& Exp. Psychiat. 42 (2011) 330e336. Diakses dari http:// www.sciencedirect.com/ pada tanggal 5 Oktober 2013.

NACBT, 2007. 'Cognitive behavioral therapy'. Diakses dari http://www.nacbt.org/whatiscbt.ht m pada tanggal 5 Oktober 2013.

Notoatmodjo, S., 2010. IImu perilaku kesehatan. Jakarta: Rineka Cipta.

Nursalam, 2003. Konsep dan penerapan metodologi penelitian ilmu keperawatan: pedoman skripsi, tesis, dan instrumen penelitian. Jakarta: Salemba Medika.

Oemarjoedi, A.K. 2003. Pendekatan cognitive behavior dalam psikoterapi. Jakarta: Kreativ Media.

Puskesmas Panarung Kota Palangka Raya, 2013. Laporan surveilans kasus Penyakit Tidak Menular bulan September 2013.

Puskesmas Panarung Kota Palangka Raya, 2013. Laporan surveilans kasus Penyakit Tidak Menular bulan Oktober 2013.

Puskesmas Panarung Kota Palangka Raya, 2013. Laporan surveilans kasus Penyakit Tidak Menular bulan Nopember 2013.

Schuurmans, J., Comijs, H., Emmelkamp, P.M., Gundy, C.M., Weijnen, I., Van Den Hout M., \& Van Dyck R., 2006. 'A randomized controlled trial of the effectiveness of cognitive-behavioral therapy and sertraline versus a waitlist control group for anxiety disorders in older adults'. Am J Geriatr Psychiatry. 2006 Mar;14(3):255$63 . \quad$ Diakses dari http://www.ncbi.nlm.nih.gov/ pada tanggal 21 Oktober 2013. 
Schuurmans, J., Comijs, H., Emmelkamp, P.M., Weijnen, I., Van Den Hout M., \& Van Dyck R., 2009. 'Longterm effectiveness and prediction of treatment outcome in cognitive behavioral therapy and sertraline for late-life anxiety disorders'. Int Psychogeriatr. 2009 Dec;21(6):1148-59. Diakses dari http://www.ncbi.nlm.nih.gov/ pada tanggal 21 Oktober 2013.

Shahni, R., Shairi, M.R., Moghaddam, M.A.A., \& Zarnaghash, M., 2013. 'Appointment the effectiveness of cognitive-behavioral treatment of pain on increasing of self-efficacy in patients with chronic pain'. Procedia-Sosial and Behavioral Sciences 84 (2013) 225-229. Diakses dari http://www.sciencedirect.com/ pada tanggal 5 Oktober 2013.

Smeltzer, Suzanne C., 2002. Buku ajar keperawatan medikal bedah: Brunner \& Sudarth. edisi 8. vol 2. Alih bahasa: Kuncara, dkk. Jakarta: EGC.

Stanley M.A., Wilson, N., Novy, D.M., Rhoades, H.M., Wagener, P., Greisinger, A.J., Cully, J.A., \& Kunik, M.E., 2009. 'Cognitive behavior therapy for generalized anxiety disorder among older adults in primary care: a randomized clinical trial'. JAMA. 2009 April 8; 301(14): 14601467. Diakses dari http://www.ncbi.nlm.nih.gov/ pada tanggal 21 Oktober 2013.

Sung, J., Woo, J.M., Kim, W., Lim, S.K., \& Chung, E.J., 2012. 'The effect of cognitive behavior therapy-based "forest therapy" program on blood pressure, salivary cortisol level, and quality of life in elderly hypertensive patients'. Clin Exp Hypertens. $\quad 2012 ; 34(1): 1-7$. Diakses dari

http://www.ncbi.nlm.nih.gov/ pada tanggal 22 Oktober 2013.
Tomey A.M. dan Alligood M. R., 2006. Nursing theorists and their work. 6th ed. USA: Mosby.

Waite, P., McManus, F., \& Shafra, R., 2012. 'Cognitive behaviour therapy for low self-esteem: a preliminary randomized controlled trial in a primary care setting'. $J$. Behav. Ther. \& Exp. Psychiat. 43 (2012) 1049e1057. Diakses dari http://www.sciencedirect.com/ pada tanggal 5 Oktober 2013.

Widiyani, Rosmha, 2013. 'Penderita hipertensi terus meningkat', 5 April 2013. Diakses dari http://www.kompas.com/ pada tanggal 5 Oktober 2013.

Zadeh, Z.F. \& Lateef, M., 2012. 'Effect of cognitive behavioural therapy (CBT) on depressed female university students in Karachi'. Procedia-Social and Behavioral Sciences 69 (2012) 798-806. Diakses dari http://www.sciencedirect.com/ pada tanggal 5 Oktober 2013. 